\title{
Current Skills Gap in Manufacturing: Towards a New Skills Framework for Factories of the Future
}

\author{
Afroditi Skevi ${ }^{1}$, Hadrien Szigeti ${ }^{2}$, Stefano Perini $^{3}$, Manuel Oliveira ${ }^{4}$, \\ Marco Taisch ${ }^{5}$, and Dimitris Kiritsis ${ }^{6}$ \\ ${ }^{1}$ Ecole Polytechnique Fédérale de Lausanne (EPFL), Lausanne, Switzerland \\ afroditi.skevi@epfl.ch \\ ${ }^{2}$ Dassault Systémes, Paris, France \\ Hadrien. SzIGETI@3ds.com \\ ${ }^{3}$ Politecnico di Milano (POLIMI), Rome, Italy \\ stefano.perini@polimi.it \\ ${ }^{4}$ SINTEF, Trondheim, Norway \\ manuel.oliveira@sintef.no \\ ${ }^{5}$ POLIMI \\ marco.taischapolimi.it \\ ${ }^{6} \mathrm{EPFL}$ \\ dimitris.kiritsis@epfl.ch
}

\begin{abstract}
In the Factories of the Future framework, cutting-edge ICT developments have been accomplished by the industry, triggering new professional needs, which lead to new learning and training needs and new roles, especially regarding high-skilled labor force. Under this light, in this paper we define and analyze further the reasons triggering what is known as a "skills gap" in the world of European and global manufacturing, before reviewing applied solutions. Missing roles and related manufacturing skills, necessary for the development and progress of Factories of the Future, are then identified, based on surveys which reveal the voices of industrial stakeholders dispersed in the international market. The present analysis was conducted in the frame of the FP7 FoF project "ManuSkills", which aims to study the use of enhanced ICT-based technologies and training methodologies to facilitate an increase of young talent interest in manufacturing and to support their training of new manufacturing skills.
\end{abstract}

Keywords: Skills Gap, Manufacturing Skills, ICT for Manufacturing, Factories of the Future, ManuSkills.

\section{$1 \quad$ Introduction}

According to the Department for Education and Skills [1] in the UK a skills shortage is defined as "A situation where there is a genuine shortage in the accessible external labor market of the type of skill being sought, and which leads to a difficulty in recruitment". Additionally, we can find an internal skills gap, where existing employees with a certain skill set are insufficient to meet the constantly renewed business 
objectives. From another perspective, given that most manufacturing positions today require at least basic STEM (Science, Technology, Engineering and Maths) skills, this phenomenon is often referred to as the STEM crisis, since not many students nowadays follow careers stemming from the STEM fields, creating thus an ominous future for manufacturing. This problem is said to be present at world-wide level; United States, Australia, China, Brazil, South Africa, India and of course Europe.

\section{Skills Shortage: The European Case}

Landing in Europe, skill deficiencies are already a critical issue. The European Company Survey [2] presents data, showing that in 2009 approximately $36 \%$ of firms belonging to EU-27 encountered trouble to hire (highly) skilled personnel. Figure 1 reveals that in 2009 a significant part of European firms experienced difficulties in tracing suitably skilled employees, especially in the domains mostly affected by the crisis. An important part of manufacturing employers (40\%) reported a higher shortage of skilled labour force [3]. Cedepof [4] identified that green occupations, vital for innovation and sustainability, suffer from skills gaps, especially when it comes to STEM skills.

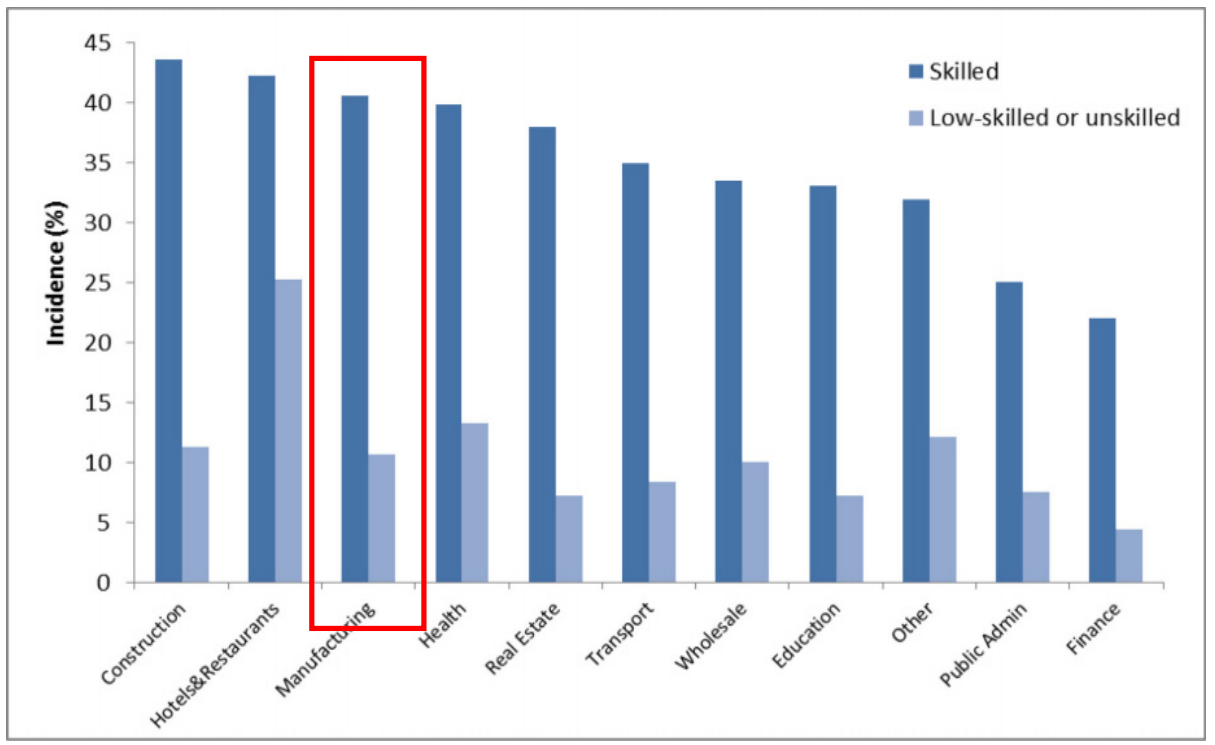

Fig. 1. Skills and labor shortages by economic sector in EU-27 (2009). Source: [3].

\section{The Missing Roles}

The global case does not seem more promising, as skills gaps seem to have an impact on the majority of the roles required in manufacturing. In the present survey we focus on roles related to highly skilled labor force. The Economist Intelligent Unit [5] 
conducted a global survey with executives from diverse industries. Almost $60 \%$ of them seemed to be worried about shortages found or anticipated in the technical or engineering field (Figure 2). Regarding the most significant skill shortages, deficient problem solving skills reached the top, with basic technical and industryemployability skills (ex. ICT literacy, self-directed learning, adaptability, communication, teamwork) following.

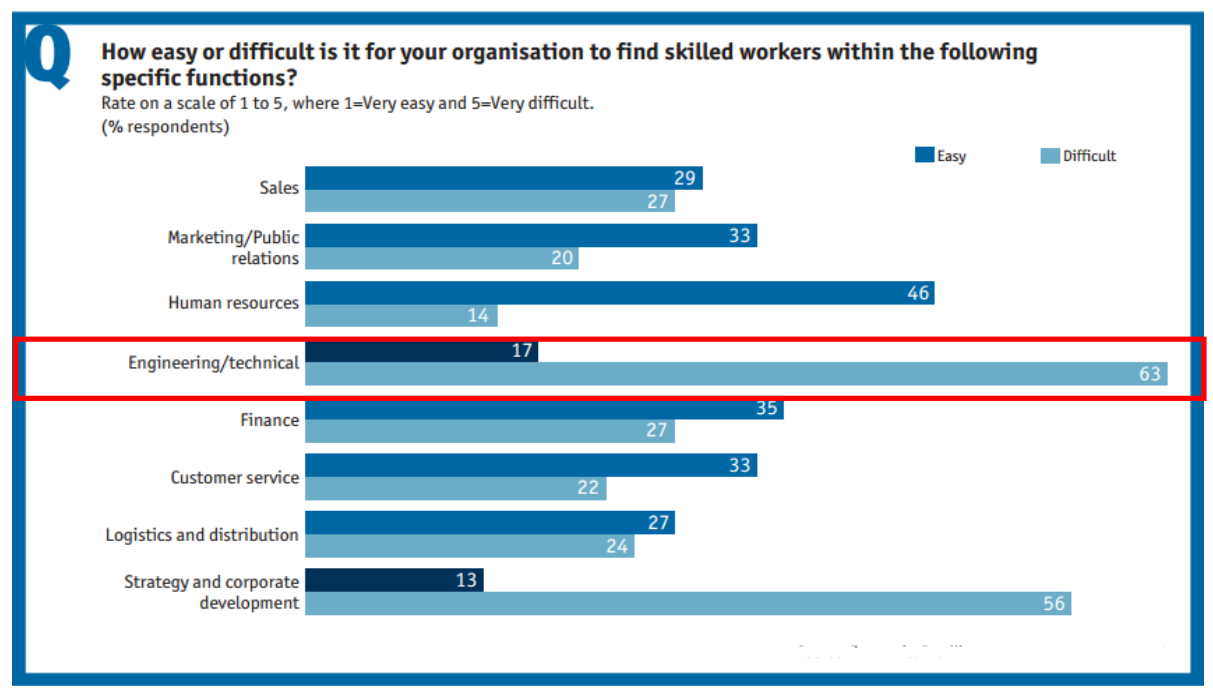

Fig. 2. Difficulty of skilled workers identification, based on specific functions. Source: [5].

The aforementioned situation rises a paradox, given the constantly increasing rate of unemployment. More specifically according to Eurostat data [6], between 2007 and 2012 most of the EU countries presented a raise above $2 \%$ in the unemployment rate of their active population with Ireland, Greece and Spain reaching peak numbers (from 10 to 18\%). Only Malta, Austria and Germany lessened their unemployed population. Even if this statistical data do not refer exclusively to manufacturing, it is widely known that also candidates of the engineering areas - often overqualified have a hard time finding the appropriate position. A skills mismatch is considered as the main factor defining this paradox, with long-term unemployment, recruitment hesitation due to economic uncertainty [7] and elastic labor demand [8] aggravating further the problem.

\section{$4 \quad$ Skills Gap Root Causes}

Many attempts have been made to explain and interpret the critical issue of skills gap. Our survey of the relevant literature identified 5 key gaps: 
- Demographic gap: an aging workforce

The rapidly aging workforce leads to skilled-labor shortages. According to Eurofound in 2011 [9], the working population (Eu27) aged between 55 and 64 grew by approximately $17 \%$ from 2000 to 2010, with manufacturing absorbing the main percentage (14\%) of the aged workforce. Employers tend to attribute the elderly staff with a high level of absenteeism, resistance to change, low flexibility and adaptability to new methods and technologies [10], thus setting doubts to the success of their retraining.

- Human Resources Management gap: outdated strategic workforce planning

Although manufacturers indicate workforce planning and labor costs first in their corporate strategy planning, when hiring new staff, they usually rely on informal suggestions, while advice from educational institutes, retraining of the existing talents and the establishment of a competency model approach are usually set aside [11], revealing a possible strong effect from cultural aspects.

- Educational gap: limited efficiency of national education and life-long learning

One of the main reasons for the global skills shortage is the weak link between what schools teach and what the job front needs. STEM education is still presenting many deficiencies. The "one-size-fits-all" approach often implemented promotes standardization, while undermining innovative approaches for STEM. In addition, the traditional school model does not leverage alternative educational programs integrating ICT-based solutions, while STEM teachers are not always fully or properly trained [12]. Regarding higher education, traditional institutions cannot afford to constantly change their curriculum following the continuously and fast-changing industrial needs [13]. Finally, when education spans much further than the K-12 frame, it is impossible for formal education to eternally claim responsibility for lifelong learners. Consequently, workers should independently self-direct their training throughout their career.

- Manufacturing Image gap: poor perception among the young generation

The widespread belief that "we don't make things anymore in Europe" [14] can discourage the younger generation from following an industrial career. Further, some of the media propagate such perceptions, ignoring the recent progress and the contribution of different manufacturing actors. Moreover, the social environment often prevents young talents from working in manufacturing, due to consolidated opinions based on experiences created by industrial standards of the past [15].

- Flexibility gap: the changing nature of work

During the last decades, the core of STEM working has radically changed. Long-term employment is hard to find, while the labor market is overwhelmed by temporary positions [16]. On the other hand, currently many companies -unwilling to invest time and money for training- favor too much outsourcing [16]. Thus, the volatility and rapid transformation consists an additional barrier for young people towards engineering. 


\section{Overview of Solutions}

The critical issue of skills shortage, is not a new problem to industrial actors, having tackled with the challenge to a degree with different levels of success. Literature indicates that some companies, especially in the high-skilled level, rely on overtime or contingent labor (such as outplacement agencies), even by addressing new workforce segments such as former army members, housewives or immigrants [11].

However, overtime hours appears as a short term solution not effectively addressing the issue of unemployment. Outsourcing, mainly used to reduce operating costs, only seems to displace the problem to other companies engaging "experts" not exclusively devoted to a certain organization. Additionally, it has negative effects on the attractiveness of skilled jobs, and may lead to an eventual loss of control over the company's processes and sub-standard quality output, while in the case of offshore outsourcing, issues may raise regarding language and communication [17].

Some industrial domains have also taken local actions to face the problem by addressing national education or vocational training institutions for bilateral training programs, in order to customize their curricula to train effectively future candidates [18].

As a step further, following the German example [19], a global European initiative could scale up these local ones, thus providing a more sustainable solution to develop required manufacturing skills, with countries with an effective program of vocational education helping other weaker countries enforce their future skilled force

Trying to achieve a solution in the long-run, governments are spending billions of dollars every year to enhance the ranks of STEM workers [14, 20,21]. The European Commission [3] has also shown an active engagement, in order to limit the impact of this phenomenon by giving guidelines, which aim to identify clearly the skill needs and supply, to effectively bridge the gap between the labor market and education.

However, the challenge here is to boost field oriented, competence based learning, scaffolded by innovative delivery mechanisms, which can raise training effectiveness. Skills standardization is a promising method, with employers communicating the skill standards they have defined to educational and technical training actors, so that they design and conduct effective training programs. As a result, employers can hire workforce with relevant skills, who boost productivity by returning faster the company's staffing investment. Further, relevant skills can be leveraged by promoting the rolemodel of life-long learners and encouraging professional mobility -if necessary with cross border skill policies and a better strategy to match people's skills to the industries' requirements.

\section{New Skills Requirements}

Behind this skills gap there is an opportunity: if education could provide more skilled workers and advanced manufacturing engineers to the industry, there would be an opportunity to radically transform the European factories, boost their competitiveness and profoundly renew the social image of manufacturing. 
In order to efficiently transform the European factories, we should get rid of this XXth Century Taylorist vision of skilled worker roles. Definition of skills and competences of the workers is far too much enclosing them inside a single industry or process specialty -such as Assembly, Injection Molding, Surface Treatments or Die Casting- while engineering and technician positions are usually written in a way that leave them navigate from industry to industry or from specialty to speciality. It doesn't mean that skilled workers should not specialize in a given kind of process, but they should be given the necessary background to make it easy for them to move from one speciality to another based on job market demand.

As stated by Manufuture consortium, representing dozens of large and small manufacturing companies in Europe, in its 2007 proposed roadmap for Factories of the Future [22], the success of European manufacturing requires a new definition of manufacturing roles: "Taylorism is contradictory to knowledge-based manufacturing. Manufacturers need to adapt to a new type of Taylorism which takes into account dynamic change and adaptation, specific human skills and the requirement of cooperation in networks. (...) Success of European manufacturing to date is mainly related to the great diversity and skills of personnel at all levels."

Based on this observation our project proposed to infer from recent Factory of the Future roadmaps the skillsets that would enable a fast adoption of breakthrough industrial concepts in Europe. We can classify the value brought by each breakthrough into 3 broad categories, as proposed by ActionPlanT roadmapping project in 2010 [23].

- On-Demand delivery of customized products through a network of manufacturing partners

Factories of the Future require production engineers capable of rapidly prototyping new manufacturing systems in Engineering To Order (ETO) model, and continuously optimize manufacturing models. Production Engineers also need to be able to reconfigure an existing manufacturing system to adapt to a change in demand or a change in design. Eventually Production Engineers need to be capable of simulating the details of the manufacturing processes, machinery kinematics, ergonomics, with maximum accuracy to allow virtual and augmented reality.

Skilled workers as well as their management need to be trained in methodologies allowing frequent design and process changes, in a context of more and more complex and configured "Built To Order" products. More and more production systems will be self-optimizing with advanced monitoring and control: skilled workers need to be able to operate them.

Eventually more engineers and skilled workers need to be capable of using modern ICT solutions to plan and optimize manufacturing tasks taking into account their entire manufacturing systems as a single "Virtual Factory" (a.k.a "Global Plant Floor"), including the network of their suppliers and distributors in order to react in the best way to all unexpected changes that may happen internally, or from their customers, or from their suppliers. 


\section{- Fast industrialization of innovative new product / process technologies}

Factories of the future also require manufacturing engineers and manufacturing managers capable of mastering the innovation life cycle in a manufacturing context, from laboratory assessment to ramp-up in production. Each new process or piece equipment will use intellectual property that it is important to identify, protect and monetize attached to new equipment and processes: this is another discipline that needs to be taught to manufacturing engineers and manufacturing managers. This leads also to training manufacturing engineers and manufacturing managers, so that they can design and launch new manufacturing business models relying on financeand science-based entrepreneurial spirit.

As production and test equipment is also improving in flexibility and precision, skilled workers and engineers need to be trained to rapidly learn how to configure and operate new pieces of equipment at their full capacity from day one. This is especially true for new processes leveraging advanced, graded, bio-, nano- or hazardous materials. An initiative promoted as part of Factories of the Future is the concept of "Teaching Factory" capable of training employees for emerging manufacturing job profiles, and assessing their skills.

\section{- Enforcement of quality and sustainability compliance while minimizing cost}

Engineers are also required more and more to run lean assessments and optimize processes efficiency enterprise-wide. They need to learn how to reconfigure state of the art operations management ICT systems that are used to monitor and control the enterprise processes in real time. Similarly, aftersales Engineers and field Technicians are required to design, simulate and run new kinds of aftersales services, such as inspection, repair or upgrade of complex products.

Eventually Factories of the Future also require more skilled workers knowledgeable about ways to ensure compliance of products, processes and services with regulatory constraints, or with industry best practices or with internal company rules. Factories of the future will require Quality Technicians capable of planning and executing preventative maintenance plans and condition-based maintenance of manufacturing equipment. Eventually more Sustainability Technicians are required to optimize end to end energy consumption and other environmental costs factors of manufacturing processes.

\section{Conclusion}

The list of manufacturing skills proposed above is the result of our research and constitutes only an example that needs to be further matured and maintained with the help of industry representatives. However we demonstrated that it is possible to link all these definitions together to increase the attractiveness of manufacturing jobs, and ease the mobility of skilled workers across manufacturing specialties, industries and geographies.

There are already many regional and national initiatives in place, very often organized by industry but also more general sometimes. As a continuation to our work, 
we now would like to identify such organizations and involve a maximum of them in the dissemination activities of our project.

An alignment with the US Manufacturing Skills Certification System, would be a complementary approach that could help adoption by a majority of stakeholders. However as long as these job positions are not mapped with actual job offers from each industry segment, there will be little appeal for students and school program managers.

Within the ManuSkills project we plan to prototype a platform that will help the industry and the academics define these manufacturing skills, and develop awareness and training programs to attract young talents to manufacturing. Experiments conducted by the consortium partners in different European countries both in the secondary and tertiary level of education, in close collaboration with industrial stakeholders, will attempt to apply and evaluate the ICT tools developed and leveraged to raise awareness and sometimes facilitate the acquisition of the aforementioned skills. As a final step -stimulating though insights for further research-, results of our studies will be used to redefine a skills framework much closer to the vision set by Factories of the Future.

Acknowledgements. The research conducted in the frame of "ManuSkills" project leading to these results has received funding from the European Community's Seventh Framework Programme (FP7/2007-2013) under grant agreement nº 609147.

\section{References}

1. Hogarth, T., Wilson, R.: Employers Skill Survey: Skills. Local Areas and Unem-ployment, Nottingham: Department for Education and Skills, DfES Report SK 39 (2001)

2. European Foundation for the Improvement of Living and Working Conditions: European Company Survey (ECS) 2009. Eurofound (2009)

3. : European Commission: Employment and Social Development in Europe 2012 - The Skill Mismatch Challenge in Europe. Commission Staff Working Document, ch. 6, Brussels, vol. 8/9 (2012)

4. Cedepof, A.: strategy for green skills? Briefing Note (2011a)

5. Economist Intelligence Unit: Plugging the Skills Gap - Shortages among plenty. The Economist (2012)

6. Eurostat: Unemployment Statistics (2012)

7. Rampell, C.: An Odd Shift in the Unemployment Curve. The New York Times (2013)

8. Ozimek, A.: An Alternative Theory of the Skills Shortage. Forbes (2013)

9. European Foundation for the Improvement of Living and Working Conditions: Employment trends and policies for older workers in the recession. Eurofound (2011)

10. Armstrong-Stassen, M., Templer, A.: Adapting training for older employees: The Canadian response to an aging workforce, Journal of Management Development, Vol. Journal of Management Development 24(1), 57-67 (2005)

11. Deloitte Touche Tohmatsu \& US Council on Competitiveness: 2010 Global Manufacturing Competitiveness Index (2010) 
12. Burke, L., Mc.Neill, J.B.: Educate to Innovate: How the Obama plan for STEM education falls short. The Heritage Foundation (2011)

13. Yang, D.: Can we Fix the Skills gap? The Forbes (2013)

14. Lindsay, E.: President Obama Presented Ideas to Accelerate Job Growth and America's Competitiveness at Jobs Council Meeting. The White House Blog (2011)

15. Harris, S.: Teenagers shun manufacturing for more glamorous desk jobs. The Engineer (2013)

16. Charette, R.: The STEM crisis is a Myth. IEEE Spectrum (2013)

17. Flat World Solutions: The pros and cons of outsourcing (2014)

18. Sennekamp, P.: EU wind industry skills shortage: over 5.000 more workers needed per year. EurActive Press Release (2013)

19. Plüss, M.: Es darf keine billige Art sein, den Lehrlingsmangel zu überbrücken”. Tages Anzeiger (2013)

20. The White House: Fact sheet: the State of the Union: President Obama's Plan to win the Future. The White House - Office of the Press Secretary (2011)

21. The LEVIN Institute: The evolving global talent pool: lessons from the BRICS countries. The State University of New York (2009)

22. Jovane, F., Westkämper, E., Williams, D.: The ManuFuture road: towards com-petitive and sustainable high-adding-value-manufacturing. Springer (2008)

23. Taisch, M., Tavola, G.: A roadmap of ICT for Manufacturing in the Horizon 2020 prospective. In: Zelm, M., Sanchis, R., Poler, R., Doumeingts, G. (eds.) Enterprise Interoperability: IESA 2012 Proceedings, ISTE Ltd \& John Wiley and Sons, Great Britain (2012) 